\title{
A COOPERAÇÃO ENTRE A FAUUSP E A SUBPREFEITURA DO ARICANDUVA PARA O PROJETO DE ESPAÇOS LIVRES - RELATO DE UMA EXPERIÊNCIA EM ANDAMENTO
}

\author{
THE COOPERATION BETWEEN FAUUSP AND THE ARICANDUVA'S CITY HALL FOR THE \\ DESIGN OF OPEN SPACES
}

\section{GONÇALVES, Fábio Mariz}

Professor doutor - Departamento de Projeto - Grupo de Disciplinas Paisagem e Ambiente da FAUUSP. E-mail: fabiomgoncalves@uol.com.br

\section{RESUMO}

Apresenta-se a experiência de desenvolver, em duas disciplinas articuladas - uma de graduação e outra de pós-graduação - um projeto de praça que foi solicitado pela subprefeitura de Aricanduva. A área, abandonada pelo poder público há anos, foi apropriada por dois clubes de futebol e por uma favela. Agora a subprefeitura pede um projeto para valorizar a entrada da avenida Aricanduva - atendendo aos interesses dos comerciantes da região. As dificuldades enfrentadas pelo projeto impediram que ele atendesse a todas as expectativas, mas tornaram a experiência didática mais interessante e proveitosa.

\section{Palavras-chave: Ensino, projeto participativo, extensão universitária.}

\begin{abstract}
A public square project was requested by the Aricanduva's city hall division, presenting an educational opportunity to develop such project as two connected disciplines - being the first one a undergraduated course and the second, a graduated course. The area has been neglected by the public service for years and it was squattered by two Soccer Clubs and a favela (shanty town). In the present time, the City Hall asked for the project aiming to add value to the Aricanduva Avenue's entrance - meeting the demands of local merchants. The project has faced many difficulties hindering the goal of fulfilling these expectations, but at doing so, it became a more useful and interesting experience.
\end{abstract}

Key words: Education, participating project, extracurricular activities.

\section{Introdução}

Em geral, as disciplinas de projeto das faculdades de arquitetura brasileiras baseiam-se no aprendizado pela vivência, os alunos são confrontados com dificuldades que devem ser superadas. Cada disciplina oferece um desafio, tema, local ou programa com diferentes graus de dificuldades a enfrentar.

A cada etapa vencida os desafios crescem em complexidade e dificuldade. Repetem-se as exigências da etapa anterior, acrescentando-se novas problemáticas e crescentes dificuldades. Pela natureza essencialmente didática, a maior parte das disciplinas exige apenas o enfrentamento das dificuldades internas à arquitetura e ao urbanismo, deixando de tratar os desafios apresentados pela realidade e suas condicionantes mais restritivas.

Os problemas relativos ao desenho, à plástica, às condicionantes construtivas, geométricas e funcionais de um projeto podem ser cobrados e tratados por qualquer disciplina, com o grau de exigência compatível com o momento da formação do aluno; porém, as dificuldades e os desafios postos pela expectativa da população usuária ou vizinha de determinada praça, ou mesmo as implicações políticas de determinada proposta ou projeto não podem ser simuladas por uma disciplina. 
Com o objetivo de colocar os alunos frente a um desafio mais concreto, selecionou-se uma demanda real posta pela Subprefeitura Aricanduva como objeto de uma disciplina articulada entre a graduação e a pós-graduação da FAUUSP.

Esta disciplina foi a primeira experiência do Laboratório para Gestão e Projeto do Espaço - Lab Espaço - criado na FAUUSP, em 2005, por iniciativa de vários professores' ${ }^{\prime}$, dos três departamentos da faculdade, que buscavam novas oportunidades de debates e experiências didáticas.

A disciplina foi organizada a partir de uma demanda da Subprefeitura Aricanduva para o desenvolvimento do projeto de uma praça singular pela sua localização - no encontro entre as avenidas Radial Leste e Aricanduva.

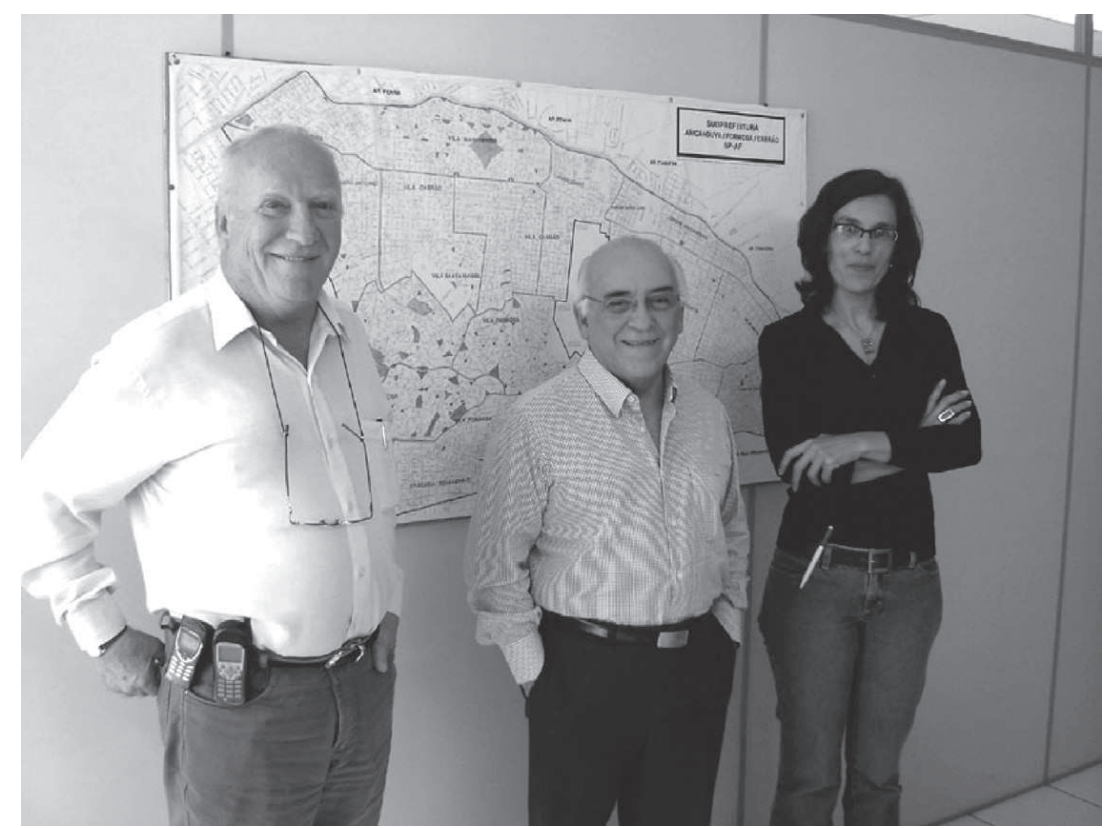

Ao centro, o subprefeito, sr. Vicente de Paula, e a arquiteta Andréa Peres Moraes

\section{A demanda}

O subprefeito Vicente de Paula elegeu esta praça por entender que ela é especialmente visível para quem entra na Subprefeitura a partir do centro da cidade, informando, também, que teria apoio de proprietários e comerciantes da região interessados na melhoria da imagem da avenida.

A "praça" nada mais é do que a área remanescente das desapropriações realizadas pelo metrô e pela Emurb para a implantação tanto da linha Leste-Oeste quanto do complexo viário que liga a avenida Aricanduva com a Marginal do Tietê. Parte da área é remanescente de desapropriação, parte constitui-se de trechos de ruas que desapareceram pela desapropriação e apenas parte é delimitada como área verde. Com o abandono e o tempo, dois clubes de futebol de várzea instalaram-se, apropriando-se do espaço. Vigas de concreto que sobraram das obras de canalização do córrego Aricanduva remanescem empilhadas há anos, em um dos lados, e barracos surgiram tanto sobre as vigas quanto em uma área contígua. Assim, depois de anos de omissão o poder público decide priorizar e intervir no espaço.

Durante as conversas esclareceu-se que seria mais interessante para os alunos, e mesmo para a Subprefeitura, que o projeto fosse desenvolvido com a participação dos diferentes agentes envolvidos - os vizinhos, os clubes de futebol e os investidores - de modo que todos participassem da discussão do projeto.

O Subprefeito achou interessante a sugestão e se firmou o acordo de que a disciplina desenvolveria o projeto, fornecendo os elementos para que as obras fossem realizadas. Enfrentar um 
projeto concreto, trabalhando com a população e os agentes envolvidos, numa disciplina de graduação, parecia complexo demais. Optou-se por desenvolver duas disciplinas paralelas: uma na pós-graduação (AUP-5835 - Ambiente e Paisagem Metropolitana, ministrada pelos professores Euler Sandeville e Fábio Mariz Gonçalves) que trabalharia com os diferentes agentes e outra na graduação (AUP-0669 - Gestão da Paisagem e do Ambiente, ministrada pelos professores Euler Sandeville e Heliana Comin Vargas) que desenvolveria e detalharia o projeto.Deste modo, a experiência tornou-se ainda mais rica, por articular alunos de graduação e pós-graduação.

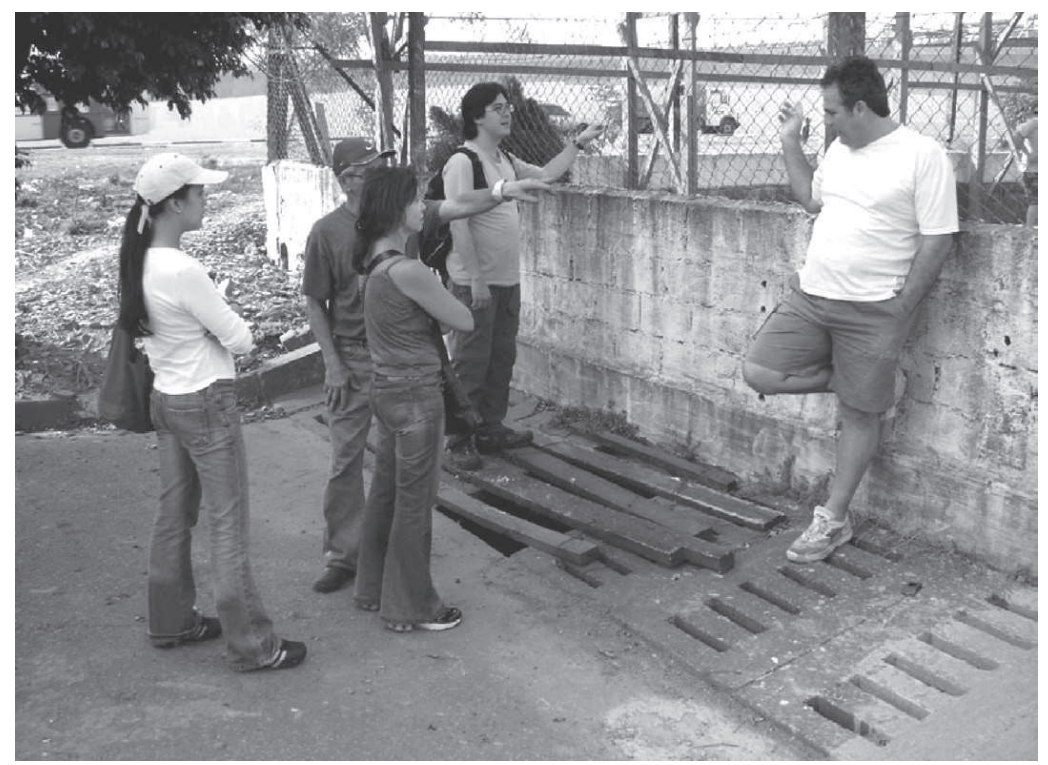

Os alunos de pós-graduação discutindo com moradores da área os problemas de drenagem

\section{O processo}

A disciplina de pós-graduação abriu os trabalhos com aulas preparatórias que tratavam do tema dos "projetos participativos" e das condicionantes ambientais, sociais e urbanísticas da área. Representantes da prefeitura como a arquiteta Andréa Peres Moraes compareceram às aulas para conversar com os alunos sobre suas expectativas e o seu entendimento das possibilidades e limitações.

Ao longo de todo o processo evitou-se filtrar as informações, buscava-se colocar os alunos diretamente em contato com os agentes e fatos. Os alunos foram a campo, recolheram as opiniões, estabeleceram os contatos com os representantes dos clubes, confrontaram os mapas e plantas fornecidas com o lugar, atualizando, corrigindo e complementando as bases.

A partir da ida a campo evidenciaram-se as contradições e os desafios do projeto. Na área da praça organizaram-se dois clubes de futebol que vêm, há anos, "equipando" e administrando o espaço. Foram estes clubes que impediram que a praça fosse tomada por barracos ou que se tornasse depósito de lixo e entulho. Contudo, estes mesmos clubes têm limitado o acesso de parte da população à área, impedindo inclusive que crianças vizinhas brinquem nas quadras nos horários ociosos.

Os dirigentes dos clubes foram os principais interlocutores no debate das propostas. Quando foram feitos os primeiros contatos a equipe foi recebida com desconfiança e reservas, depois, como possível aliada na consolidação da sua permanência.

Para os alunos a experiência de entrevistar diretamente os representantes, de escutar seus discursos e de debater os significados e as estratégias subjacentes foi enriquecedora. Percebeu-se que os clubes, cientes da situação irregular, preocupavam-se com os rumos do nosso trabalho. Buscavam legitimar sua permanência contando das ações sociais que empreendem, das festas que promovem, dos investimentos feitos na área e dos momentos em que abrem suas 
quadras para crianças da vizinhança. Mostravam fotos amareladas e desbotadas pelo tempo para ilustrar que estão no local há bastante tempo. Contavam suas histórias e conquistas, seu compromisso com a história do bairro e das várzeas.

Nas pesquisas de campo ficou evidente que os clubes já estão assimilados pela vizinhança. O exíguo comércio das imediações caracteriza-se pela venda de bebidas nos fins de semana para os jogadores e torcedores presentes. Parte dos vizinhos é "sócia" dos clubes que, inclusive, são usados como canais de reivindicação e protesto dos vizinhos junto à prefeitura para que esta solucione problemas como enchente e limpeza da área.

Uma grande creche mantida pela igreja, distante poucas quadras da praça, não poder contar com a área para atividades ao ar livre, porém ninguém percebe que possa fazer alguma coisa para alterar este fato.

As ruas próximas revelam a quantidade de crianças moradoras na área. Muitas delas foram vistas brincando por ali, mas nenhum dos pais confirmou a necessidade de "conquistar" ou de "ganhar" uma praça diante das suas casas.

Em 10 de setembro de 2005, foi organizada uma reunião, em um colégio próximo à área, com os objetivos de eligir expectativas e de conciliar compromissos de participação. A Subprefeitura encarregou-se de fazer os convites e convocar a população para a ocasião. Contudo, contrariando nossas expectativas, apenas os dirigentes dos clubes compareceram.

Apresentaram-se três cenários possíveis, com diferentes graus de intervenção: no primeiro, propunha-se que as quadras dos clubes permaneceriam, sofrendo apenas ajustes necessários para abrir uma passagem entre elas; no segundo, propunha-se que os clubes passariam a compartilhar o mesmo campo e, com a eliminação de um deles, ganhar-se-ia um espaço para convívio e lazer da população (parquinho, quiosques, etc.); no terceiro, propunha-se apenas um campo, novo, sem vínculo com os anteriores, sem "donos", sem clubes para geri-lo, no centro de uma praça pública e qualificada.

Inicialmente, os "donos" dos clubes pareciam dispostos a aceitar a segunda hipótese, de juntar os clubes compartilhando uma única quadra. Contudo, como a reunião não oferecia outros interlocutores (a vizinhança, moradores ou sequer um dos filiados ao clube que não fosse da diretoria) resolveu-se fazer mais uma reunião, no prazo de duas semanas, no mesmo local, na esperança de um maior comparecimento.

Talvez por não haver interesse da população, talvez por não se sentir à vontade para debater o destino da área dos clubes diante dos seus donos, talvez por incompetência ou má vontade da prefeitura em convocar a população, a reunião seguinte, em 24 de setembro de 2005, não teve comparecimento muito maior. Compareceram os mesmos dirigentes e mais um dos moradores da favela instalada sobre o depósito de vigas, como "representante" da população residente na área.

Este morador fez um discurso marcante para o rumo das discussões - afirmou que aceitaria ter sua casa removida da área caso fosse do interesse e para o bem de todos, só não aceitaria a remoção se fosse para "plantar árvores ou fazer praça para maconheiros, para isso não".

Os dirigentes dos clubes, sentindo que dominavam o diálogo, resolveram recrudescer rejeitando qualquer proposta para a área, elevaram o tom de voz e disseram ser os donos das suas quadras, que estavam protegidos, por vereadores amigos, de qualquer proposta que contrariasse seus interesses. Abandonaram a reunião, avaliando que não teriam por que aceitar qualquer redução nas suas áreas.

Na semana seguinte debateu-se com os alunos o significado daquela atitude dos clubes. Ficou evidente que o projeto chegava a um impasse e o próprio papel da equipe em cheque. 


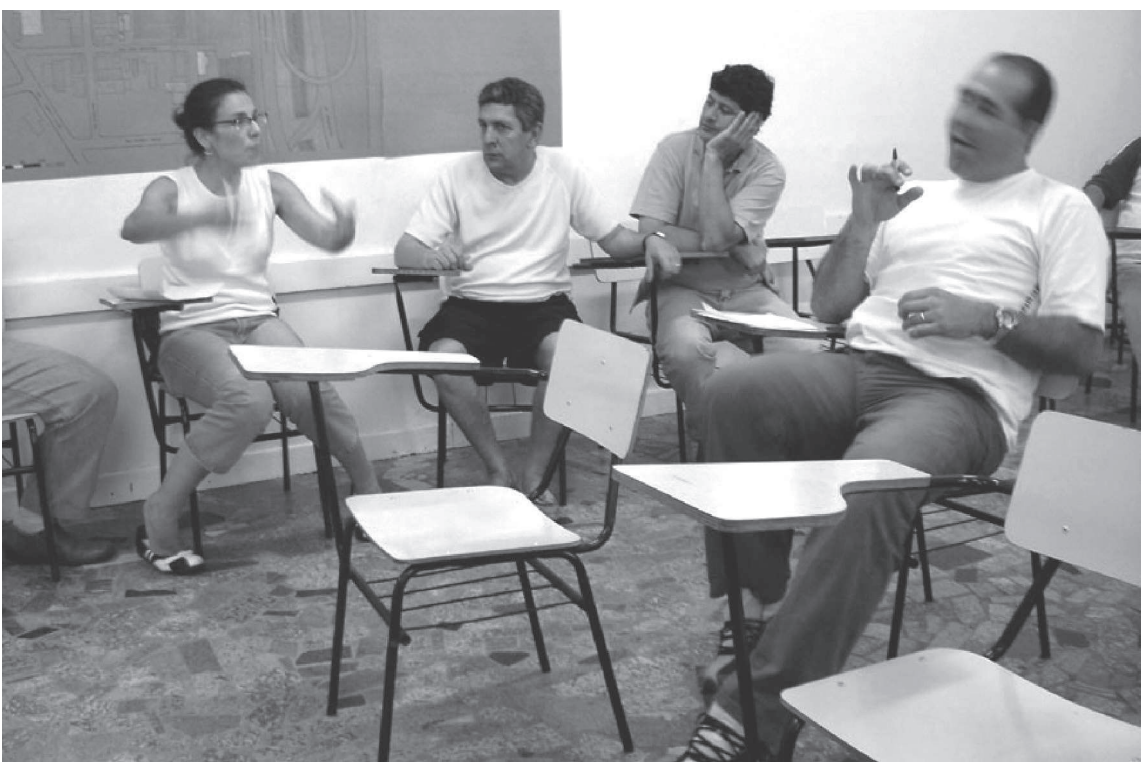

Representantes da prefeitura, dirigentes dos clubes e alunos discutindo, em escola próxima à praça, as propostas apresentadas

Em 29 de setembro de 2005, realizou-se um seminário, na cidade universitária, com a presença dos alunos de graduação (AUP-0669) e da Subprefeitura. O seminário foi iniciado pelos colegas Eugênio Queiroga, Vladimir Bartalini e Fábio Robba que apresentaram a discussão acerca da apropriação dos espaços públicos. Em seguida, os alunos realizaram a apresentação dos cenários propostos para os clubes e dos resultados das reuniões em campo.

Depois, debatendo-se as alternativas e o processo, cobrou-se dos representantes da Subprefeitura posição definitiva acerca das propostas. $O$ chefe do gabinete do Subprefeito acabou escolhendo a hipótese mais radical, a terceira. Pediu um prazo para discutir o assunto com o Subprefeito e confirmar a escolha, mas dizia que "certamente" era a hipótese que traria mais benefícios para a população, reafirmando o caráter público da área e a autoridade da prefeitura em detrimento da autoridade dos clubes. A ocasião foi extremamente interessante para os alunos, pois puderam assistir ao vivo, na sala de aula, com a participação de colegas da pós-graduação e professores, os diferentes representantes da prefeitura exporem os prós e contras de cada alternativa, refletirem em voz alta acerca das reais possibilidades institucionais e políticas de implementação de cada hipótese.

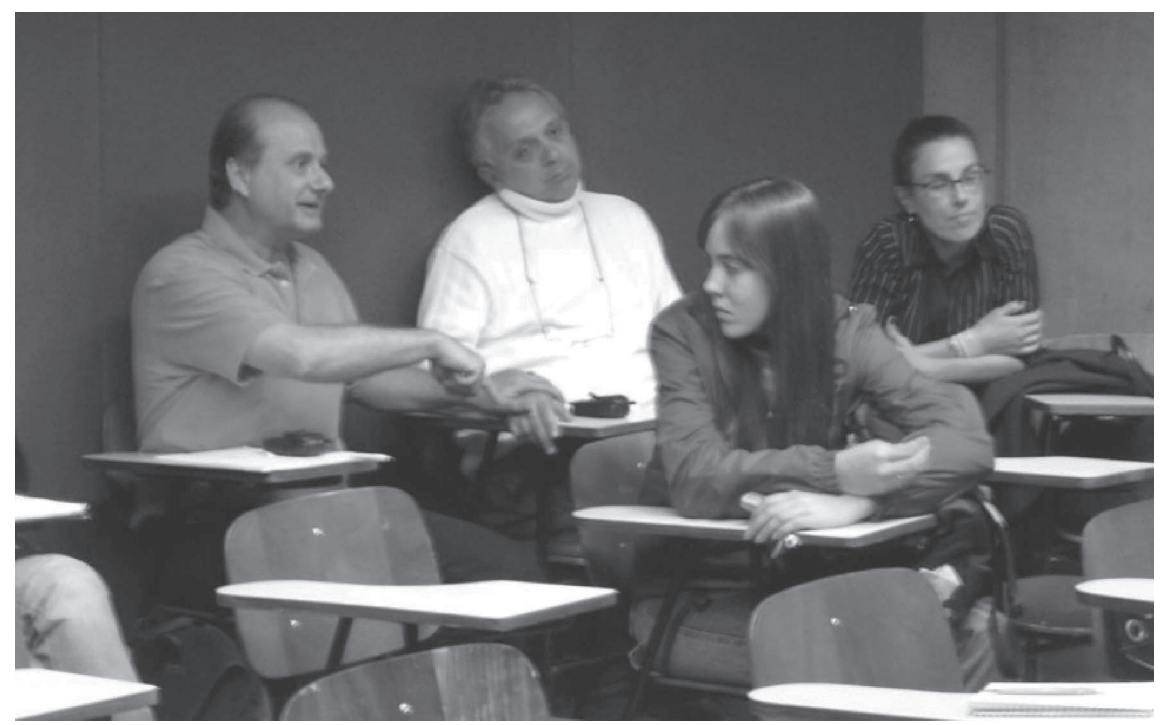

Alunos e representantes da prefeitura discutindo, na FAUUSP, as alternativas do projeto 
Embora os demais agentes não estivessem presentes (vizinhos, clubes e moradores), suas posições foram vividamente expostas pelos alunos de pós-graduação.

Pela demora em obter a confirmação da escolha pela prefeitura, marcou-se mais uma reunião, agora na subprefeitura, em 27 de outubro de 2005, quando foi confirmada pelo subprefeito a escolha da opção três. O levantamento topográfico da área, que há muito tempo havia sido solicitado, demorou a chegar, mas vieram em tempo de alimentar o trabalho dos alunos da graduação que desenvolveram a hipótese escolhida, detalhando pisos, caminhos, plantio e edificações.

No fim do semestre foi entregue à prefeitura o projeto desenvolvido pelos alunos.

Em março de 2006 a arquiteta Andréa Peres Moraes informou que o processo de licitação para a execução da obra segue seus passos.

\section{As dificuldades}

É certo que o processo de trabalho sofreu as vicissitudes de um projeto real. Houve dificuldade em estabelecer contato com a população, de colocar frente a frente os agentes vinculados ao projeto e de encontrar um projeto que agradasse plenamente estudantes e professores. Faltou apoio e organização da prefeitura para estabelecer um processo mais democrático e abrir debate dos projetos com a população.

Faltou clareza dos interesses envolvidos. Em determinado momento parecia que comerciantes da avenida Aricanduva tinham interesse em retirar os clubes do local meramente para melhorar a "imagem" da avenida, hipótese que não foi confirmada. Em outro momento parecia que os moradores estavam receosos que os clubes fossem retirados, por não acreditar que a prefeitura poderia cuidar adequadamente da área ou por ter interesse direto na permanência dos clubes. Em certos momentos parecia que os clubes impediam a criminalidade de se instalar na área, em outros, eles pareciam ser os próprios "criminosos". Até mesmo a razão do interesse da própria Subprefeitura não ficou plenamente esclarecida.

Os alunos em vários momentos tiveram dificuldades em atender às expectativas dos professores e mesmo às necessidades do projeto. Os desenhos apareciam com lentidão e sem a qualidade necessária para a sua compreensão pelos interlocutores. Mesmo os alunos da pósgraduação, em sua maioria arquitetos formados, desenhavam sem desenvoltura.

Durante as reuniões com os representantes dos clubes a condução dos debates ficou a cargo dos professores por falta de maturidade, por timidez ou por falta de articulação dos alunos presentes. Os professores prefeririam que os alunos conduzissem as conversas e apresentações, mas, por incapacidade, falta de vontade ou receio de não responder às necessidades não houve meio de fazê-los tomar a frente dos encontros. Durante o desenvolvimento do projeto executivo foi notável a dificuldade dos alunos de se organizarem em uma única equipe. Habituados a trabalhar em pequenas equipes, junto aos amigos escolhidos com liberdade para propor o que bem entendem, sem ter que excluir uma alternativa ou forma, os alunos demonstraram dificuldades em debater em grupo as soluções e formas propostas para caminhos, espaços e demais elementos. Demonstravam desapontamento quando esta ou aquela sugestão de um era preterida pelo coletivo. Desapontados, pouco ajudavam no desenvolvimento da hipótese escolhida.

Os alunos da pós-graduação ficaram visivelmente frustrados pelo resultado não ter contemplado uma solução de consenso que permitisse a permanência dos clubes de futebol e o ganho da praça pela população, conciliando as expectativas das agremiações, dos vizinhos, dos moradores, da prefeitura e deles próprios. 


\section{O balanço}

Oartigo 2ํำ das Diretrizes Curriculares Nacionais para o Ensino de Graduação em Arquitetura e Urbanismo, de 1995, no seu parágrafo único estabelece que: "Os cursos de arquitetura e urbanismo, ao definirem suas propostas pedagógicas, devem assegurar a formação de profissionais generalistas, aptos a compreender e traduzir as necessidades de indivíduos, grupos sociais e comunidade, com relação à concepção, organização e construção do espaço exterior e interior, abrangendo o urbanismo, a edificação, o paisagismo, bem como a conservação e a valorização do patrimônio construído, proteção do equilíbrio do ambiente natural e à utilização racional dos recursos disponíveis."

Assim, colocar os alunos frente às demandas e dificuldades reais conseqüentes da incapacidade do poder público e, em última análise, da própria sociedade de formular projetos mais inclusivos e democráticos é fundamental para o entendimento do real papel do projeto e por fim do próprio profissional arquiteto.

Repetir projetos comprometidos unicamente com a satisfação dos alunos e professores e suas expectativas e temas empobrece a discussão. Muitas vezes a sociedade comparece nos projetos desenvolvidos em ateliê, de maneira estereotipada ou idealizada, como se ora fosse completamente aberta às utopias democratizantes (ou fascistas) ora fosse condenada à repetição das soluções adotadas pelo mercado imobiliário. As disciplinas demonstraram ao aluno o contraditório e nebuloso jogo de interesses na apropriação dos espaços livres urbanos e a dificuldade do profissional em encontrar a justa medida do seu papel e dos compromissos éticos, sociais e ambientais inerentes ao seu trabalho.

Colocado frente ao fato de que seu desenho não se constrói apenas com as variáveis aprendidas nas disciplinas de tecnologia, história e projeto o aluno se vê restrito em sua liberdade e criatividade. Ao perceber que o desenho também é construído pelos agentes e usuários do espaço, o aluno tem dificuldade de enxergar seu espaço criativo, suas atribuições e a beleza e poesia do processo coletivo.

Mesmo com as dificuldades enfrentadas dentro e fora do ambiente de ensino, a experiência foi avaliada de modo positivo tanto pelos professores e alunos como pela própria subprefeitura. $\bigcirc$ projeto foi o melhor possível dentro das limitações impostas pela realidade, as mesmas limitações que muito contribuíram para o processo de aprendizado tanto dos alunos quanto das próprias instituições - faculdade e prefeitura.

Neste semestre desenvolve-se a terceira disciplina em parceria com a Subprefeitura do Aricanduva. O subprefeito manifestou dúvidas acerca da eficiência e qualidade das estratégias adotadas para mitigar os problemas de enchentes na bacia do córrego Aricanduva. Montou-se uma disciplina para estudar alternativas e medidas complementares que possam ser tomadas pela administração pública frente ao problema. Outros temas já foram sugeridos para trabalhos em disciplinas futuras.

Acredita-se que, com a prática, alunos, professores, técnicos e políticos entenderão melhor os benefícios e alcance desse trabalho conjunto. A sala de aula, além de servir melhor ao próprio ensino, tornar-se um fórum de debate e reflexão da própria sociedade.

A prática projetual encontra uma nova dimensão para os alunos: torna-se o instrumento da construção do consenso, do acordo entre os agentes transformadores do espaço urbano, e o arquiteto, o mediador deste diálogo. 


\section{Nota}

(1) Profa. Dra. Clice Mazzilli (AUP-PV), Prof. Dr. Eduardo Nobre (AUP-PL), Prof. Dr. Eugênio Queiroga (AUP-PA), Prof. Dr. Euler Sandeville (AUP-PA), Prof. Dr. Fabio Mariz Gonçalves (AUP-PA), Prof. Dr. João Whitaker (AUP-PL), Profa. Dra. Mônica Junqueira (AUH), Prof. Dr. Nuno Fonseca (AUP-PL) e Prof. Dr. Reginaldo Ronconi (AUT). 